\title{
Correction to: Clinical and oncological benefits of left hepatectomy for Bismuth type I/II perihilar cholangiocarcinoma
}

\author{
Yoshitsugu Nakanishi ${ }^{1}$ - Satoshi Hirano ${ }^{1} \cdot$ Keisuke Okamura ${ }^{1} \cdot$ Takahiro Tsuchikawa $^{1} \cdot$ Toru Nakamura $^{1}$. \\ Takehiro Noji ${ }^{1}$. Toshimichi Asano ${ }^{1}$ - Aya Matsui ${ }^{1} \cdot$ Kimitaka Tanaka $^{1} \cdot$ Soichi Murakami ${ }^{1}$. Yuma Ebihara ${ }^{1}$. \\ Yo Kurashima $^{1} \cdot$ Yusuke Watanabe $^{1} \cdot$ Toshiaki Shichinohe $^{1}$
}

Published online: 18 November 2021

( ) The Author(s) under exclusive licence to Springer Nature Singapore Pte Ltd. 2021

\section{Correction to: Surgery Today} https://doi.org/10.1007/s00595-021-02401-7

In the original publication, Reference 12 was published incorrectly. The correct version of Reference 12 is given in this Correction as below:

12. Nakanishi Y, Tsuchikawa T, Okamura K, Nakamura T, Tamoto E, Noji T, et al. Risk factors for a high Comprehensive Complication Index score after major hepatectomy for biliary cancer: a study of 229 patients at a single institution. HPB (Oxford). 2016;18:735-41.
The original publication has been corrected.

Publisher's Note Springer Nature remains neutral with regard to jurisdictional claims in published maps and institutional affiliations.

The original article can be found online at https://doi.org/10.1007/ s00595-021-02401-7.

Yoshitsugu Nakanishi

y.nakanishi@mac.com

1 Department of Gastroenterological Surgery II, Faculty

of Medicine, Hokkaido University, N-15, W-7, Kita-Ku,

Sapporo, Hokkaido 060-8638, Japan 